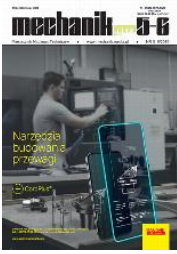

How to cite this article:

Authors: Piotr Wyżga, Piotr Klimczyk, Jolanta Cyboroń, Paweł Figiel

Title of article: "SPS sintering of nitride ceramics"

Mechanik, No. 5-6 (2019)

DOI: https://doi.org/10.17814/mechanik.2019.5-6.41

\title{
SPS sintering of nitride ceramics
}

\author{
PIOTR WYŻGA \\ PIOTR KLIMCZYK \\ JOLANTA CYBOROŃ \\ PAWEL FIGIEL *
}

Dr inż. Piotr Wyżga, piotr.wyzga@ios.krakow.pl, https://orcid.org/0000-0003-3103-5292 - Sieć Badawcza Łukasiewicz - Instytut Zaawansowanych Technologii Wytwarzania

Dr inż. Piotr Klimczyk, piotr.klimczyk@ios.krakow.pl, https://orcid.org/0000-0002-8060-1388 - Sieć Badawcza Łukasiewicz - Instytut Zaawansowanych Technologii Wytwarzania

Dr inż. Jolanta Cyboroń, jolanta.cyboron@ios.krakow.pl, https://orcid.org/0000-0002-8338-8180 - Sieć Badawcza Łukasiewicz - Instytut Zaawansowanych Technologii Wytwarzania

Dr inż. Paweł Figiel, pawel.figiel@ios.krakow.pl, https://orcid.org/0000-0001-9805-7715- Sieć Badawcza Łukasiewicz - Instytut Zaawansowanych Technologii Wytwarzania

Due to the unique properties of ceramics materials based on nitride, it could be used in the broadly understood technique. However, obtaining silicon nitride materials requires it to use the advanced methods of manufacturing, mostly because this material is difficult to sinter. Dense ceramic sinters were obtained from the system $\mathrm{Si}_{3} \mathrm{~N}_{4}-\mathrm{Al}_{2} \mathrm{O}_{3}-\mathrm{Y}_{2} \mathrm{O}_{3}$ by applied pulsed current - SPS/FAST method (Spark Plasma Sintering/Field Assisted Sintering Technique). The sintering parameters of the initial mixture were optimized to obtain the highest possible sinter properties, such as: density, Young's modulus, hardness and fracture toughness. In the presented work the influence of pressure and pulse current, used in the SPS/FAST method, on sinterability and on selected physical and mechanical properties of the obtained materials was analyzed. The purpose of introducing the $\mathrm{Al}_{2} \mathrm{O}_{3}$ and $\mathrm{Y}_{2} \mathrm{O}_{3}$ additions to the $\mathrm{Si}_{3} \mathrm{~N}_{4}$ matrix was to activate the hard-to-sinter silicon nitride powder and consequently to achieve a high density of the sintered samples. The best properties were characterized by sinter obtained in $1700^{\circ} \mathrm{C}$ and under pressure $63 \mathrm{MPa}$; the holding time at sintering temperature was $15 \mathrm{~min}$. The density of the obtained sample has reached $\mathbf{9 8 \%}$ theoretical value, and the other parameters were: Young's modulus - $298 \mathrm{GPa}$, Vickers hardness - 17,7 GPa, fracture toughness - $6 \mathrm{MPa} \cdot \mathrm{m}^{1 / 2}$.

KEYWORDS: $\mathrm{Si}_{3} \mathrm{~N}_{4}$, SPS sintering, Young's modulus, hardness

\section{Introduction}

$\mathrm{Si}_{3} \mathrm{~N}_{4}$ silicon nitride is a ceramic material belonging to the so-called technical ceramics. Due to its unique properties, $\mathrm{Si}_{3} \mathrm{~N}_{4}$ matrix ceramics are one of the most popular materials used in the broadly defined technique. Ceramics with a silicon nitride matrix are characterized by good chemical and oxidation resistance, high hardness and surface crack resistance. These materials can work at elevated temperatures, because they retain very good mechanical properties. Due to this, nitride ceramics are widely used in many industries, including aviation, military, chemical, metallurgical, food, fuel, electronics industries, as well as in medicine - nitride ceramics are used to make, for example, machining tools, bearings, engine parts and gas turbines.

$\mathrm{Si}_{3} \mathrm{~N}_{4}$ components are found in dosing valves for chemical pumps and pumps operating at high temperature or aggressive environments. Silicon nitride ensures a longer service life of machinery and equipment, and prevents unnecessary stops and failures - often even entire production lines.

Due to favourable combination of properties of $\mathrm{Si}_{3} \mathrm{~N}_{4}$ matrix ceramics, further modifications to the composition of this group of materials are justified, both in terms of their current and future applications.

Silicon nitride has low self-diffusion rate and is classified as difficult to sinter. Silicon nitride materials in the form of dense sinters with good properties are obtained by free sintering using activators - most often oxides and their mixtures, e.g. $\mathrm{MgO}, \mathrm{Y}_{2} \mathrm{O}_{3}, \mathrm{Al}_{2} \mathrm{O}_{3}$. During sintering, activators form the liquid phase and facilitate the consolidation of $\mathrm{Si}_{3} \mathrm{~N}_{4}[2,3]$. Due to activators, relatively well-concentrated materials can be obtained by free 
sintering. In this method, however, the material's sustaining time at sintering temperature is long ( $60 \div 90 \mathrm{~min})$, which causes an increase in grain size and thus deterioration in mechanical properties of the material. To avoid grain growth during sintering $\mathrm{Si}_{3} \mathrm{~N}_{4}$, various physical factors are used to activate consolidation mechanisms and significantly reduce the total time of the material compaction process. These factors can be e.g. elevated or ultrahigh pressure (from $30 \mathrm{MPa}$ to $8 \mathrm{GPa}$ ), microwave radiation or pulse current - their impact is used in the processes of sintering with pulse current SPS, microwave sintering and high pressure HPHT (high pressure - high temperature) [4].

Free sintering usually produces sinters with relative density of up to about $96 \%$, while high-pressure sintering HPHT allows materials with density exceeding $99 \%$ of the theoretical value to be obtained. However, high density does not guarantee optimal mechanical properties, including Young's modulus or hardness. During sintering HPHT, high stress is created in the material under high pressure, often causing cracking of samples.

The SPS (spark plasma sintering) method is an effective sintering method, combining the advantages of increased pressure, pulse current and a relatively short process time [5]. It uses impulse current to heat the compressed greenbody in the graphite matrix (fig. 1).

The SPS method is gaining more and more popularity because it enables sintering of materials from various groups (metallic, ceramic, composite) - both electrically conductive and insulators - including hard-sintered materials, such as carbides and borides classified as ultra-high melting ceramics, with a melting point above $3000^{\circ} \mathrm{C}$ (e.g. $\mathrm{TaC}, \mathrm{TiC}, \mathrm{ZrC}, \mathrm{NbC}, \mathrm{TaB}_{2}, \mathrm{ZrB}_{2}$ ) or silicon nitride. Due to the direct heating of the charge and the short process time, the SPS method is characterized by high energy efficiency, which makes it a cost-effective and ecological technique.

$\mathrm{Si}_{3} \mathrm{~N}_{4}-\mathrm{Al}_{2} \mathrm{O}_{3}-\mathrm{Y}_{2} \mathrm{O}_{3}$ composite mixture made using commercial nano- and micro-powders were sintered by SPS. The sintering process was optimized and the properties of the materials obtained were determined: apparent density, Young's modulus, Vickers hardness, and surface crack resistance.

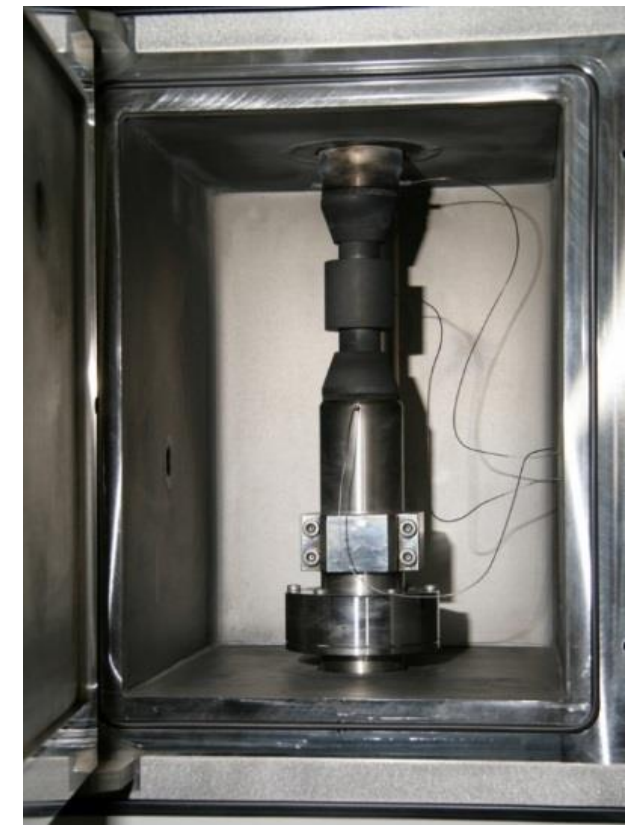

Fig. 1. SPS sintering system- sintering chamber with prepared charge

\section{Research material and methodology}

The following powders were used to prepare the mixtures:

- $\mathrm{Si}_{3} \mathrm{~N}_{4}$ from H.C. Starck - medium grain size $0.5 \div 0.7 \mu \mathrm{m}$ (grade M11),

- $\mathrm{Al}_{2} \mathrm{O}_{3}$ by $\mathrm{ALCOA}$ - medium grain size $0.3 \div 0.6 \mu \mathrm{m}$ (grade $\mathrm{A} 16 \mathrm{SG}$ ),

- Sigma Aldrich $\mathrm{Y}_{2} \mathrm{O}_{3}$ nano-powder - with an average grain size $<50 \mathrm{~nm}$.

The following mass fractions of individual components were preserved in the mix: $88 \% \mathrm{Si}_{3} \mathrm{~N}_{4}, 6 \% \mathrm{Al}_{2} \mathrm{O}_{3}$ and $6 \% \mathrm{Y}_{2} \mathrm{O}_{3}$. The mix was homogenized in a Fritsch Pulverisette 6 planetary mill using a grinding bowl $(250 \mathrm{ml}$ capacity) and grinders (5 mm diameter) made of silicon nitride. The rotational speed was $200 \mathrm{rpm}$ and the homogenization time was 1 hour. Isopropyl alcohol was used as wetting medium. The mix was then dried at $100^{\circ} \mathrm{C}$ for $5 \mathrm{~h}$. The mixes were pre-pressed at a pressure of $110 \mathrm{MPa}$ in a $20 \mathrm{~mm}$ diameter graphite matrix and 
then placed in the SPS chamber. Sinters with a height of approx. $5 \mathrm{~mm}$ were obtained. The samples were sintered at a temperature in the range of $1450 \div 1700^{\circ} \mathrm{C}$ at a pressure of $63 \mathrm{MPa}$; holding time at sintering temperature was 4 and $15 \mathrm{~min}$. Sintering was carried out under an argon atmosphere. The SPS sintering device is schematically shown in fig. 2.

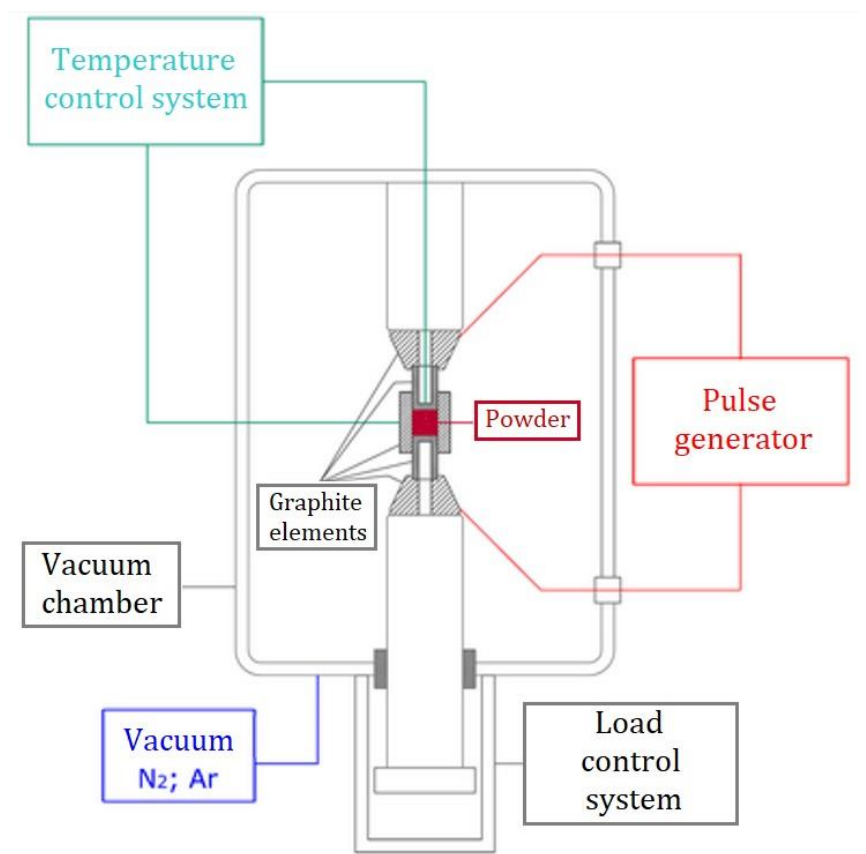

Fig. 2. Diagram of the SPS device

Phase analysis of the materials was performed by X-ray diffraction (XRD) on an Empyrean II diffractometer from PANalytical, using filtered $\mathrm{Cu} K \alpha$ radiation $\left(\lambda_{\mathrm{Cu}}=1.5406 \AA\right.$ Å). HighScore Plus software and ICDD-PDF4 + 2016 databases were used to identify the phases.

The microstructure analysis of composites was carried out using a scanning microscope (SEM) JSM-6460LV from JEOL, equipped with an EDS INCA X-act Energy $350 \mathrm{X}$-ray spectrometer from Oxford Instruments.

The density of samples was determined by the hydrostatic method in accordance with PN-EN 623-2 standard [6], and the Young's module - by the ultrasonic method with the use of the Panametrix EPOCH 3 flaw detector. Longitudinal and transverse wave velocities were determined using sample thickness and the time of passage of the ultrasonic pulse trough material. The ultrasonic method is one of the non-destructive methods for determining the elastic constants of materials.

Hardness measurements were made with the Vickers Hardness Tester FLC-50VX by FUTURE-TECH using a load of $9.81 \mathrm{~N}(1 \mathrm{~kg})$.

Fracture toughness of samples was determined by the Vickers indenter method. The marks were created under a load of $294.3 \mathrm{~N}$ (30 kg). Because the ratio of crack length to half the diagonal of the impression was greater than 2.5 , it was classified as a radial crack.

\section{Results}

\section{Phase composition analysis}

Fig. 3 shows examples of diffraction patterns of silicon nitride sinters obtained at $1550^{\circ} \mathrm{C}$ and $1700^{\circ} \mathrm{C}$. Analysis of the phase composition showed the presence of the $\alpha$ and $\beta$ phase $\mathrm{Si}_{3} \mathrm{~N}_{4}$. The diffractograms did not show reflections from sintering activators. The number of $\alpha$ and $\beta$ phases in the samples varies depending on the sintering temperature.

The phase composition and the share of the $\beta$ phase in silicon nitride in the entire cross-section of sintering optimization temperature are presented in tab. I.

Proportion of $\mathrm{Si}_{3} \mathrm{~N}_{4} \beta$ phase in the material varies from $18 \%$ to $89 \%$ with increasing temperature and sintering time extension. The $\alpha \rightarrow \beta$ transformation is a phenomenon usually occurring at temperatures above $1400^{\circ} \mathrm{C}$, favourably affecting the homogeneity of the microstructure and mechanical properties of the material (e.g. resistance to cracking or hardness) $[7,8]$. 


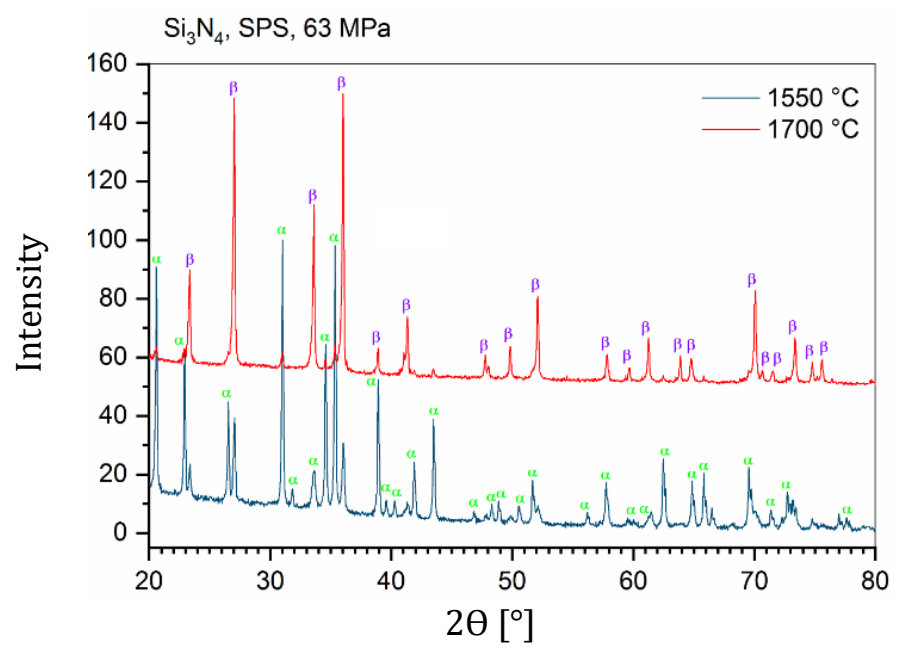

Fig. 3. Analysis of the phase composition of the samples

$\left(\mathrm{Si}_{3} \mathrm{~N}_{4}-\mathrm{Al}_{2} \mathrm{O}_{3}-\mathrm{Y}_{2} \mathrm{O}_{3}\right)$

TABLE I. Phase composition of sinters based on $\mathrm{Si}_{3} \mathrm{~N}_{4}$

\begin{tabular}{|l|c|c|}
\hline \multirow{2}{*}{ Sample } & \multicolumn{2}{|c|}{ Phase composition [wt. \%] } \\
\cline { 2 - 3 } & $\alpha \mathrm{Si}_{3} \mathrm{~N}_{4}$ & $\beta \mathrm{Si}_{3} \mathrm{~N}_{4}$ \\
\hline $1550^{\circ} \mathrm{C} / 4^{\prime}$ & 82 & 18 \\
\hline $1600^{\circ} \mathrm{C} / 4^{\prime}$ & 75 & 25 \\
\hline $1650^{\circ} \mathrm{C} / 4^{\prime}$ & 65 & 35 \\
\hline $1700^{\circ} \mathrm{C} / 4^{\prime}$ & 39 & 61 \\
\hline $1700^{\circ} \mathrm{C} / 15^{\prime}$ & 11 & 89 \\
\hline
\end{tabular}

\section{Microstructure of sinters}

The microstructure is shown in fig. $4 . \mathrm{Si}_{3} \mathrm{~N}_{4}$ grains in sintered silicon nitride are poorly visible, because they are small in size. Still, it can be said that the material is very well compacted. The porosity in the material is not visible in the microstructures.

a)

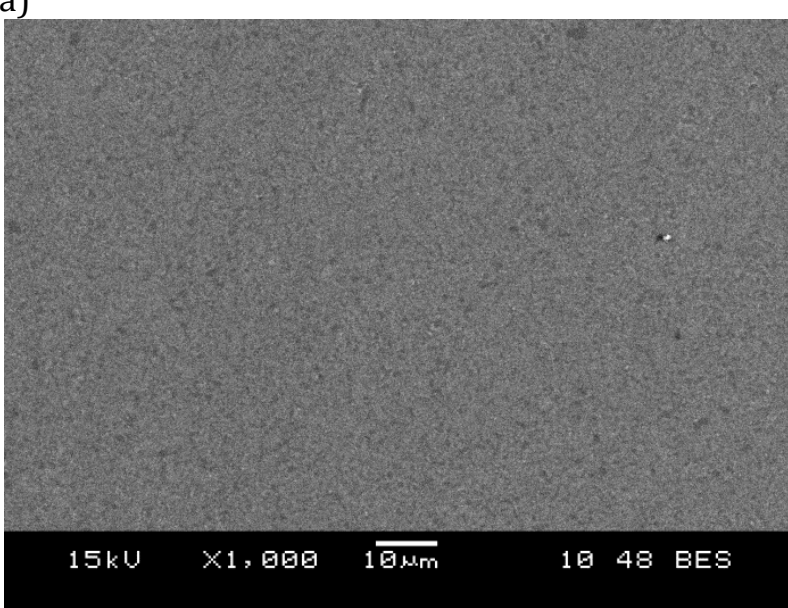

b)

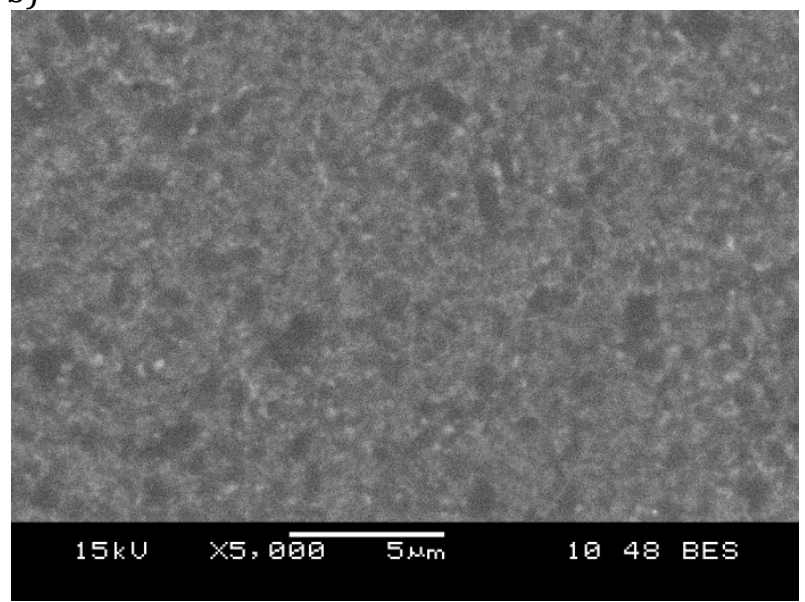

Fig. 4. Microstructure of sinters obtained by the SPS method $\left(1650^{\circ} \mathrm{C} / 4^{\prime} / 63 \mathrm{MPa}\right)$

\section{Selected physical and mechanical properties}

Results of measurements of selected physical and mechanical properties of silicon nitride sinters obtained by the SPS method at different temperatures are presented in tab. II. The analysis of sinter density and modulus of elasticity confirms the positive effect of pressure $(63 \mathrm{MPa})$ and pulse current. As part of the author's previous research [7], the $\mathrm{Si}_{3} \mathrm{~N}_{4}$ material was obtained by free sintering at $1680^{\circ} \mathrm{C}$ for 60 min (holding time at sintering temperature). The maximum sinter density that could be obtained at that time and Young's modulus were 
$3 \mathrm{~g} / \mathrm{cm}^{3}$ and $241 \mathrm{GPa}$, respectively. For comparison: when sintering by SPS, already at $1550^{\circ} \mathrm{C}$, the density was higher and amounted to $3.18 \mathrm{~g} / \mathrm{cm}^{3}$. The $\mathrm{Si}_{3} \mathrm{~N}_{4}$ sintering process by the SPS method was optimized to ensure the highest density and Young's modulus (fig. 5).

The density and Young's modulus of sinters increases with increasing temperature. The optimization process proceeded to a temperature of $1700^{\circ} \mathrm{C}$, in which the holding time at sintering temperature was extended from 4 to $15 \mathrm{~min}$. The longer sintering time resulted in additional sinter compaction and an increase in its Young's modulus of elasticity.

TABLE II. Selected properties of materials based on $\mathrm{Si}_{3} \mathbf{N}_{4}$

\begin{tabular}{|l|c|c|c|c|}
\hline \multicolumn{1}{|c|}{ Sample } & $\begin{array}{c}\text { Density } \\
{\left[\mathrm{g} / \mathrm{cm}^{3}\right]}\end{array}$ & $\begin{array}{c}\text { Young's modulus } E \\
{[\mathrm{GPa}]}\end{array}$ & $\begin{array}{c}\text { Hardness } H V \\
{[\mathrm{GPa}]}\end{array}$ & $\begin{array}{c}\text { Crack resistance } K_{\text {IcHV }} \\
{\left[\mathrm{MPa} \cdot \mathrm{m}^{1 / 2}\right]}\end{array}$ \\
\hline \multicolumn{5}{|c|}{$\mathrm{Si}_{3} \mathrm{~N}_{4}-\mathrm{Al}_{2} \mathrm{O}_{3}-\mathrm{Y}_{2} \mathrm{O}_{3}$} \\
\hline $1450^{\circ} \mathrm{C} / 4^{\prime}$ & $2.62 \pm 0.01$ & - & - & - \\
\hline $1500^{\circ} \mathrm{C} / 4^{\prime}$ & $2.85 \pm 0.01$ & $219 \pm 2$ & - & - \\
\hline $1550^{\circ} \mathrm{C} / 4^{\prime}$ & $3.18 \pm 0.01$ & $296 \pm 6$ & $\mathbf{1 7 . 6} \pm \mathbf{0 . 3}$ & $4.9 \pm 0.2$ \\
\hline $1600^{\circ} \mathrm{C} / 4^{\prime}$ & $3.21 \pm 0.01$ & $299 \pm 7$ & $17.2 \pm 0.1$ & $4.9 \pm 0.2$ \\
\hline $1650^{\circ} \mathrm{C} / 4^{\prime}$ & $3.22 \pm 0.01$ & $299 \pm 6$ & $16.2 \pm 0.9$ & $5.2 \pm 0.1$ \\
\hline $1700^{\circ} \mathrm{C} / 4^{\prime}$ & $3.21 \pm 0.01$ & $294 \pm 6$ & $16.3 \pm 0.4$ & $5.4 \pm 0.2$ \\
\hline $1700^{\circ} \mathrm{C} / 15^{\prime}$ & $\mathbf{3 . 2 4} \pm \mathbf{0 . 0 1}$ & $\mathbf{2 9 8} \pm \mathbf{5}$ & $15.4 \pm 0.2$ & $\mathbf{6 . 0} \pm \mathbf{0 . 2}$ \\
\hline
\end{tabular}

a)

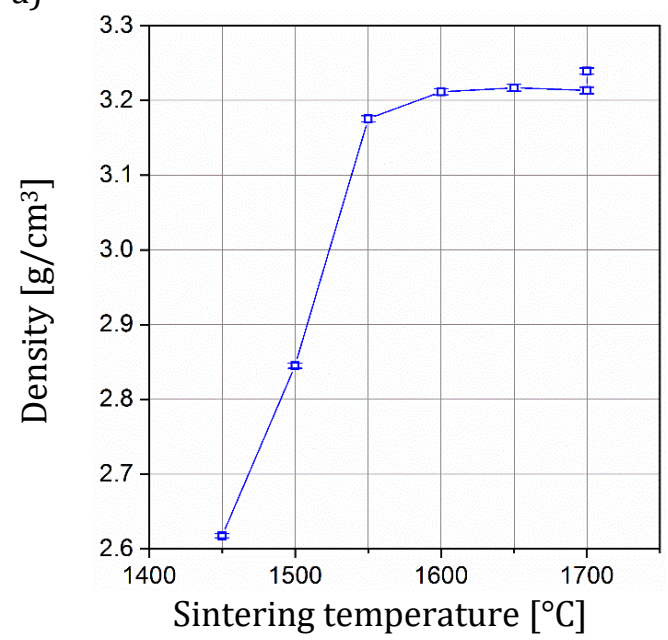

b)

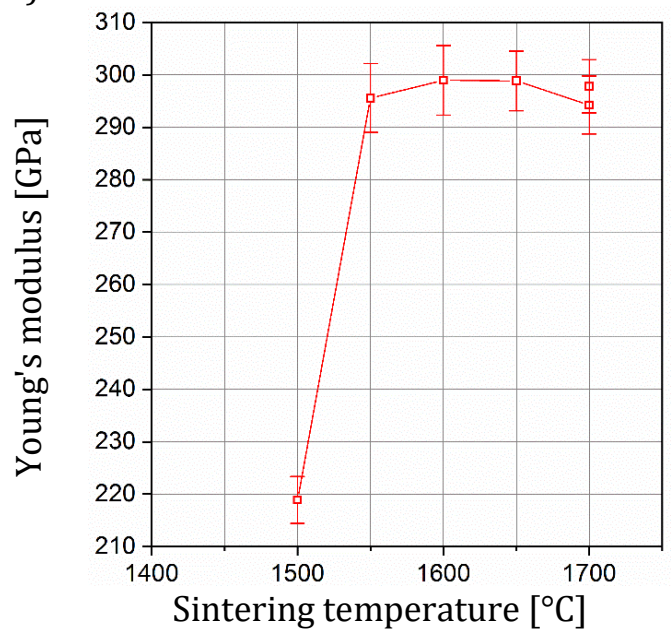

Fig. 5. Optimization of the sintering process for $\mathrm{Si}_{3} \mathrm{~N}_{4}$ material by the SPS method: a) density, b) Young's modulus

a)

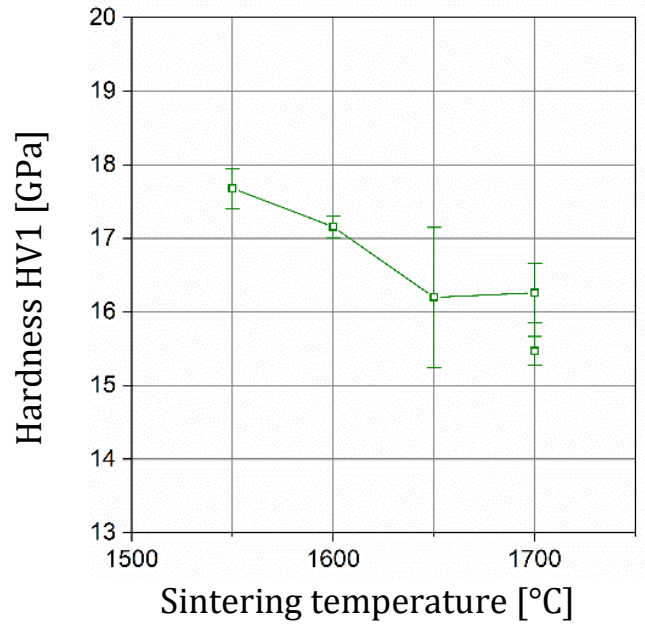

b)

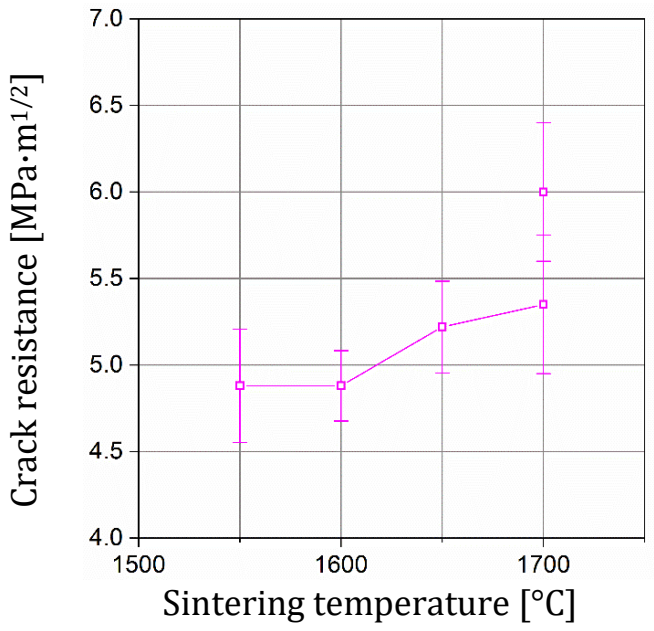

Fig. 6. Selected mechanical properties of the $\mathrm{Si}_{3} \mathrm{~N}_{4}$ sinter obtained by the SPS method: a) hardness, b) fracture toughness 
The sinter had the highest hardness obtained at $1550^{\circ} \mathrm{C}$ (fig. 5a), and the best resistance to surface cracking - sinter obtained at $1700^{\circ} \mathrm{C}$ for 15 minutes (fig. $5 \mathrm{~b}$ ).

The hardness of $\mathrm{Si}_{3} \mathrm{~N}_{4}$ samples decreases as the sintering temperature increases, while the surface crack resistance increases. These changes are caused by changes in the phase composition (transformation $\alpha \mathrm{Si}_{3} \mathrm{~N}_{4} \rightarrow \beta \mathrm{Si}_{3} \mathrm{~N}_{4}$ ) and the microstructure of the sintered material - there is grain growth associated with an increase in temperature and prolonged sintering time. Material with increased density and crack resistance was obtained.

The research showed a large application potential of silicon nitride materials. The composite obtained has a crack resistance level of $K_{\mathrm{ICHV}} 6 \mathrm{MPa} \cdot \mathrm{m}^{1 / 2}$. The possibility of using this type of materials for the production of cutting blades seems particularly attractive.

\section{Conclusions}

- It has been shown that the degree of phase transformation of $\alpha \mathrm{Si}_{3} \mathrm{~N}_{4}$ into $\beta \mathrm{Si}_{3} \mathrm{~N}_{4}$ increases with increasing temperature and sintering time extension and reaches a maximum of $71 \%$ for the considered process parameters. Due to the phase transformation, the fracture toughness increased from 4.9 to 6 $\mathrm{MPa} \cdot \mathrm{m}^{1 / 2}$.

- Due to the SPS method, the time and material sintering temperature can be significantly reduced, which can bring measurable economic benefits. For example, to obtain ceramics based on $\mathrm{Si}_{3} \mathrm{~N}_{4}$ by free sintering, a temperature of $1680^{\circ} \mathrm{C}$ is required, and the total process time - including the stages of heating, sintering and cooling the charge and furnace - is up to several hours, while in the case of the SPS method sintering takes place at $1550^{\circ} \mathrm{C}$, and the total process time is just tens of minutes. Of course, it should be taken into account that the charge in free sintering processes is usually much larger/more numerous than in SPS processes, therefore the unit cost of sinter is relatively low. In many situations it is necessary to quickly obtain small elements - then the SPS method is more effective.

- The resulting sinters with a silicon nitride matrix, which are characterized by a high degree of compaction and good mechanical properties, are especially useful for the production of cutting blades intended for the demanding machining of difficult-to-machine super alloys, such as Inconel. Such ceramics can also be used to produce wear-resistant, small machine and equipment components, e.g. ball bearings or matrix inserts, improving their service life.

The work was financed partly from the funds for the statutory activity of the tukasiewicz Research Network - Institute of Advanced Manufacturing Technologies and partly from the DURACER project, entitled "Ceramic composites reinforced with super-hard particles for cutting tools with high abrasion resistance", co-financed by the National Center for Research and Development under the program MERA.NET (contract No. M-ERA.NET2/2017/1/2018).

\section{REFERENCES}

[1] Qadir A., Fogarassy Z., Horváth Z.E., Balazsib K., Balazsi C. "Effect of the oxidization of $\mathrm{Si}_{3} \mathrm{~N}_{4}$ powder on the microstructural and mechanical properties of hot isostatic pressed silicon nitride". Ceramics International. 44 (2018): 14601-14609.

[2] Pelleg J. "Diffusion in $\mathrm{Si}_{3} \mathrm{~N}_{4}$ ". In: Diffusion in Ceramics. January 2016, DOI: 10.1007/978-3-319-18437115.

[3] Mengyong S., Qinggang L., Shifeng H., Xin C. "The densification of $\mathrm{Si}_{3} \mathrm{~N}_{4}$ ceramics using different additives via microwave sintering". Journal of the Ceramic Society of Japan. 122, 10 (2014): 914-916.

[4] Ratzker B., Sokol M., Kalabukhov S., Frage N. "High-pressure spark plasma sintering of silicon nitride with LiF additive". Journal of the European Ceramic Society. 38, 4 (2018): 1271-1277.

[5] Huang J.-L., Nayak P.K. "Strengthening alumina ceramic matrix nanocomposites using spark plasma sintering". Advances in Ceramic Matrix Composites. (2014): 218-234.

[6] European Standard EN 623-2, Advanced Technical Ceramics - Monolithic Ceramics - General and Textural Properties - Part 2 - Determination of Density and Porosity.

[7] Wyżga P., Mashimo T., Yoshiasa A., Jaworska L., Klimczyk P. "The effect of high-energy methods of forming on the sintering behaviour and properties of $\mathrm{Si}_{3} \mathrm{~N}_{4}$-based materials". International Journal of Refractory Metals and Hard Materials. 80 (2019): 277-285.

[8] Hampshire S. "Silicon nitride ceramics - review of structure, processing and properties". Journal of Achievements in Materials and Manufacturing Engineering. 24, 1 (2007): 43-50. 